13.4

\title{
PIC-моделирование генерации СВЧ-излучения в отражательном триоде радиального типа с расходящимся замагниченным электронным пучком
}

\author{
(C) A.Е. Дубинов ${ }^{1,2}$, В.П. Тараканов ${ }^{3,4}$ \\ ${ }^{1}$ Российский федеральный ядерный центр - Всероссийский научно-исследовательский институт экспериментальной \\ фризики, Саров, Нижегородская обл., Россия \\ ${ }^{2}$ Саровский фризико-технический институт, Саров, Нижегородская обл., Россия \\ ${ }^{3}$ Объединенный институт высоких температур РАН, Москва, Россия \\ ${ }^{4}$ Национальный исследовательский ядерный университет „МИФИ“, Москва, Россия \\ E-mail: dubinov-ae@yandex.ru
}

Поступило в Редакцию 6 ноября 2019г.

В окончательной редакции 6 ноября 2019 г.

Принято к публикации 12 ноября 2019г.

\begin{abstract}
Проведено particle-in-cell-моделирование отражательного триода с радиально расходящимся замагниченным электронным пучком. Изучалась динамика электронного пучка и генерационных характеристик отражательного триода. Показано, что в нем формируется два виртуальных катода. Рассчитано, что при токе пучка $I_{0}=5 \mathrm{kA}$ и потенциале катода $U_{c}=-100 \mathrm{kV}$ пиковая мощность СВЧ-излучения достигает $P=19 \mathrm{MW}$. В спектре СВЧ-излучения имеется пик на частоте $v=5.2 \mathrm{GHz}$.
\end{abstract}

Ключевые слова: отражательный триод, РІС-моделирование, виртуальный катод, СВЧ-излучение.

DOI: 10.21883/PJTF.2020.04.49044.18099

Отражательные триоды относятся к мощным СВЧ-генераторам с виртуальным катодом (ВК). Их изобрели почти одновременно - в 1979г. - в США [1] и в СССР [2]. Многие лаборатории развивают отражательные триоды и исследуют их возможности до настоящего времени [3-7]. На них достигнут уровень мощности СВЧ-излучения в сотни мегаватт, а спектр излучения приходится, как правило, на дециметровый диапазон длин волн. Обзор СВЧ-генераторов с ВК, в частности отражательных триодов, представлен B $[8]$.

Еще одна разновидность приборов с ВК с радиальным электронным пучком, сходящимся к оси системы, была изобретена в 1989г. [9]. Такой прибор впервые был опробован экспериментально в [10]. Основная особенность такого генератора - баллистическая радиальная фокусировка электронного пучка вблизи оси камеры, что позволяет увеличить плотность электронов в ВК. Такие генераторы с ВК были названы коаксиальными виркаторами, однако их следовало бы называть виркаторами с радиально сходящимся пучком. Коаксиальные виркаторы со сходящимся пучком также широко исследуются во многих лабораториях [11-14]. Укажем, что были созданы и исследованы СВЧ-генераторы с ВК и с расходящимся от оси электронным пучком $[15,16]$.

СВЧ-генераторы с ВК, виркаторы и отражательные триоды имеют, как правило, короткую длину области генерации, сравнимую с длиной волны, в то время как в других СВЧ-генераторах, таких как лампы бегущей волны и лампы обратной волны (ЛОВ), области генерации могут иметь протяженность вдоль оси генератора в несколько десятков длин волн.

Недавно был сформирован новый класс СВЧ-приборов с радиальным релятивистским электронным пучком и длительным взаимодействием пучка с СВЧ-волной (ЛОВ [17], клистрон [18], времяпролетный генератор [19]), причем в таких генераторах используют как радиально сходящиеся, так и расходящиеся электронные пучки. Для продолжительного радиального движения электронного пучка необходимы магнитные поля с линиями поля, направленными вдоль радиуса. Поэтому электронные пучки в генераторах [17-19] замагничены.

В связи с этим представляется актуальным рассмотрение особенностей СВЧ-генерации в отражательном триоде с радиально расходящимся замагниченным электронным пучком, имеющем протяженную область взаимодействия. Цель настоящей работы состоит в изучении генерационных возможностей такого генератора с помощью particle-in-cell-моделирования (PIC-моделирования).

Для моделирования отражательного триода использовался 2.5D-вариант PIC-кода „КАRAT“ [20], который многократно применялся для задач подобного типа - самосогласованного расчета динамики релятивистских электронных пучков с формированием ВК и электромагнитного поля, в том числе СВЧ-излучения $[21,22]$. 


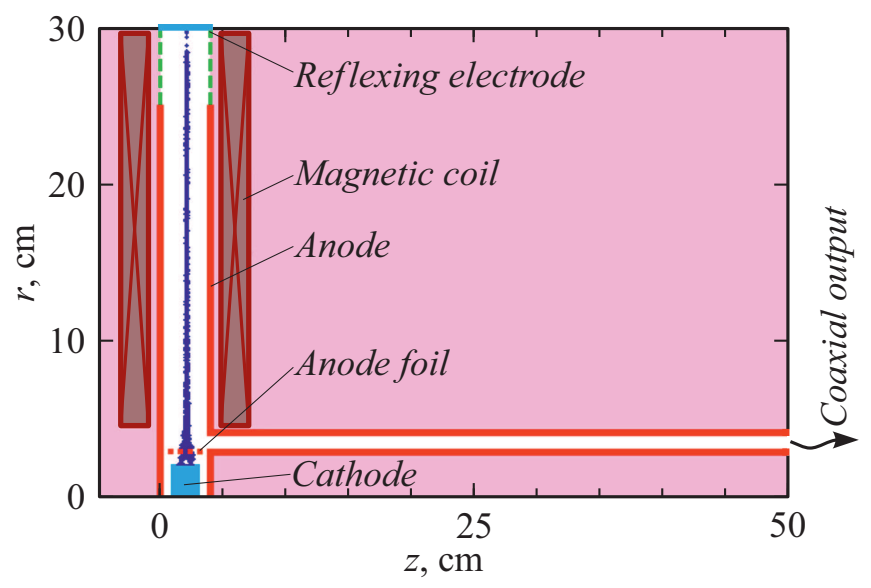

Рис. 1. Геометрия отражательного триода с радиальным электронным пучком.

Геометрия моделируемого отражательного триода в координатах $(z, r)$ представлена на рис. 1. Триод представляет собой вакуумированную полость в форме диска радиусом $R=30 \mathrm{~cm}$ и высотой $H=4 \mathrm{~cm}$. Вблизи оси диска устанавливается цилиндрический катод радиусом $r_{c}=2 \mathrm{~cm}$ и высотой $h_{c}=2 \mathrm{~cm}$, боковая поверхность которого способна эмитировать сильноточный электронный пучок. На периферии дисковой полости устанавливается отражающий электрод. На расстоянии $d=1 \mathrm{~cm}$ от боковой поверхности катода располагается анодная сетка, полностью прозрачная для электронов. К правой боковой поверхности анодной полости присоединена вакуумная коаксиальная передающая линия с внешним и внутренним радиусами $R_{\text {line }}=4 \mathrm{~cm}$ и $r_{\text {line }}=3 \mathrm{~cm}$ (волновое сопротивление $\rho \approx 17.3 \Omega$ ). На расчетную область накладывалось магнитное поле двух дисковых соленоидов с намотками противоположных направлений. Они возбуждали в полости стационарное почти однородное магнитное поле радиального направления величиной $B_{r}=1 \mathrm{~T}$. Считалось, что торцевые стенки полости находятся под постоянным нулевым потенциалом $\left(U_{a}=0 \mathrm{kV}\right)$, а на катод и отражающий электрод подавались отрицательные потенциалы $\left(U_{c}\right.$ и $U_{r}$ соответственно). Предполагалось также, что эмиссия электронов с поверхности отражающего электрода отсутствует. Этого можно добиться применением специального диэлектрического покрытия его внутренней поверхности.

Задавалось, что в момент времени $t=0$ начиналась эмиссия электронного пучка с боковой поверхности катода с постоянным по времени значением тока пучка $I_{0}$. Далее приведены результаты моделирования динамики электронов и генерационных характеристик для одного из вариантов питания отражательного триода.
При заданных потенциалах катода и отражающего электрода $U_{c}=-100 \mathrm{kV}$ и $U_{r}=-120 \mathrm{kV}$ конфигурация пучка с током $I_{0}=5 \mathrm{kA}$ показана на рис. 1 . Видно, что пучок фокусируется вблизи диодной области. Эта фокусировка обусловлена тем, что магнитное поле здесь неоднородно и линии магнитного поля искривлены.

Мгновенный фазовый портрет электронного пучка представлен на рис. 2. На нем видно, что в пучке сформированы два ВК. О возможности формирования двух ВК в отражательном триоде в промежутке между анодной сеткой и отражающим электродом сообщалось в [23]. В соответствии с классификацией ВК, данной в [8], в [23] указано, что $\mathrm{VC}_{1}$ представляет собой колебательный ВК, природа которого связана с превышением током пучка значения предельного вакуумного тока. Его осцилляции являются источником мощного CВЧ-излучения. $\mathrm{VC}_{2}$ представляет собой отражательный ВК, который может существовать стационарно, как, например, в отражательных клистронах. В нашем случае $\mathrm{VC}_{2}$ также осциллирует благодаря осцилляциям $\mathrm{VC}_{1}$.

Следовательно, зазор выходной коаксиальной передающей линии лучше всего размещать вблизи $\mathrm{VC}_{1}$, что и было предусмотрено при разработке геометрии данного отражательного триода.

Для оценки значений СВЧ-мощности, генерируемой в отражательном триоде, вычислялся поток вектора Пойнтинга в коаксиальной передающей линии в сечении $z=49 \mathrm{~cm}$. На рис. 3, $a$ показано изменение этого потока во времени $\tau=20 \mathrm{~ns}$. Расчеты дают, что пиковая мощность отражательного триода может достигать $P=19 \mathrm{MW}$.

Для установления спектральных характеристик СВЧ-полей, генерируемых отражательным триодом,

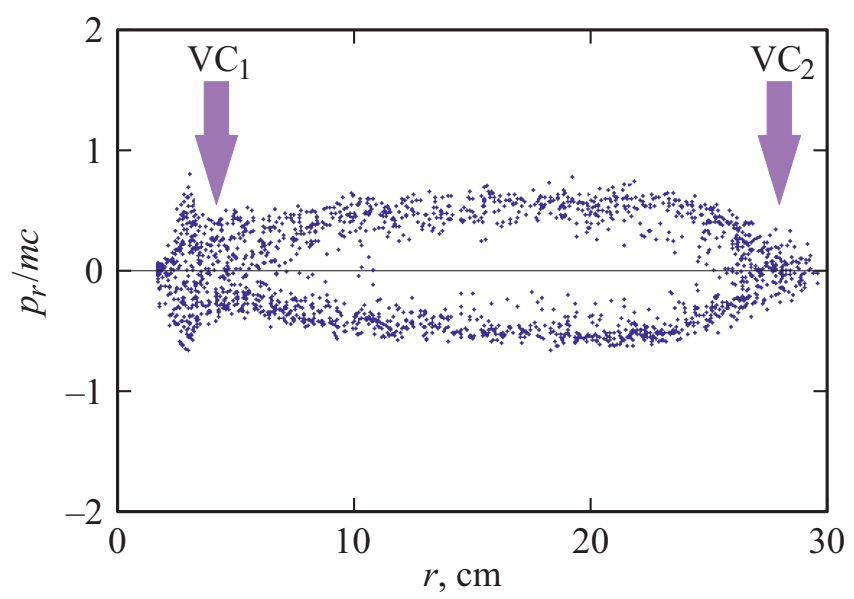

Рис. 2. Мгновенный фазовый портрет электронного пучка с двумя ВК (по осям: $r$ - радиальная координата электронов, $p_{r} / m c$ - радиальная компонента импульса электронов, нормированная на $m c$, где $m-$ масса электрона, $c$ - скорость света). 

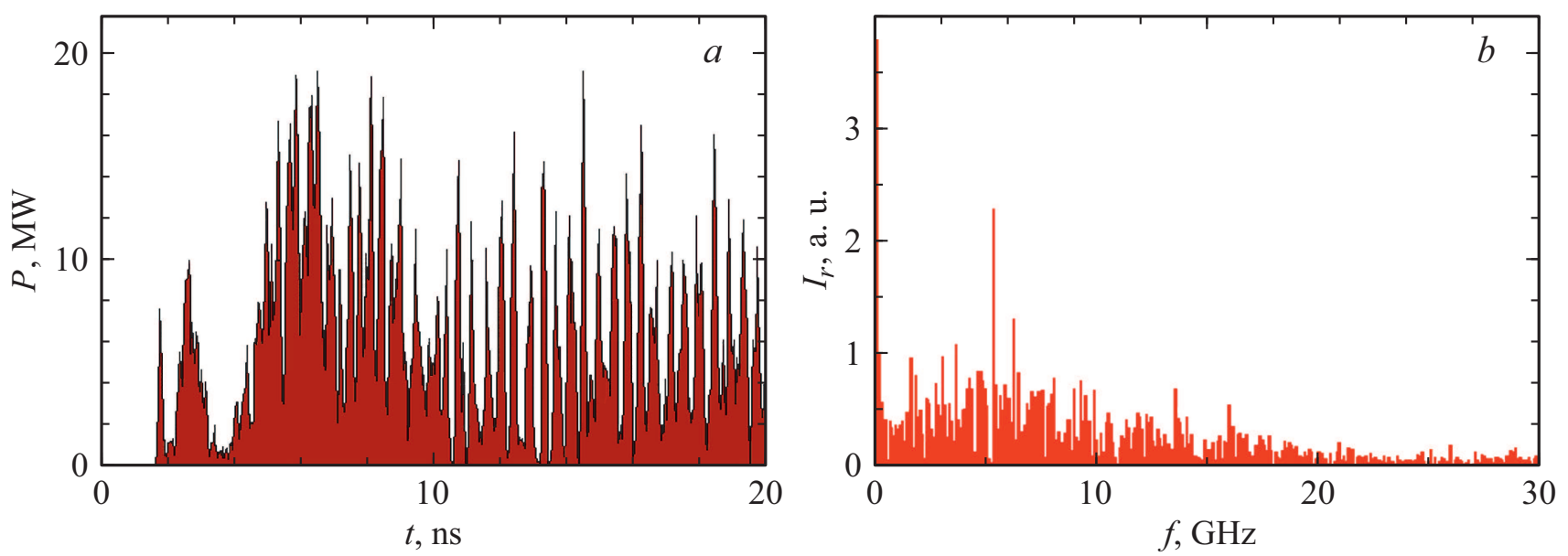

Рис. 3. Генерационные характеристики отражательного триода. $a-$ изменение потока вектора Пойнтинга $P$ в коаксиальной передающей линии в сечении $z=49 \mathrm{~cm} ; b-$ спектр СВЧ-излучения радиальной компоненты тока $I_{r}$.

вычислялись фурье-спектры колебаний тока электронного пучка, промодулированного колебаниями $\mathrm{VC}_{1}$. Анализ спектров позволил найти значения частот генерируемого СВЧ-поля.

На рис. 3, $b$ показан спектр СВЧ-полей отражательного триода. Он имеет вид, характерный для шумоподобного сигнала. Диапазон СВЧ-генерации отражательного триода приходится на интервал от 0 до $20 \mathrm{GHz}$. При этом можно выделить максимум, который лежит вблизи частоты $v=5.2 \mathrm{GHz}$.

Таким образом, в работе проведено РІС-моделирование отражательного триода с радиально расходящимся замагниченным электронным пучком. Исследована динамика электронного пучка и генерационных характеристик отражательного триода. Показано, что в нем формируется два ВК. С помощью расчета установлено, что при токе пучка $I_{0}=5 \mathrm{kA}$ и потенциале катода $U_{c}=-100 \mathrm{kV}$ пиковая мощность СВЧ-излучения достигает $P=19 \mathrm{MW}$. В спектре СВЧ-излучения наблюдается пик на частоте $v=5.2 \mathrm{GHz}$.

\section{Конфликт интересов}

Авторы заявляют, что у них нет конфликта интересов.

\section{Список литературы}

[1] Kapetanakos C.A., Sprangle P.A., Mahaffey R.A., Golden J. US Patent 4150340. 17.04.1979.

[2] Диденко А.Н., Красик Я.Е., Перелыгин С.Ф., Фоменко Г.П. // Письма в ЖТФ. 1979. Т. 5. В. 6. С. 321-324.

[3] Hanjo H., Nakagawa Y. // J. Appl. Phys. 1991. V. 70. N 2. P. $1004-1010$

[4] Дубинов А.Е., Коновалов И.В., Рожнов И.В., Селемир В.Д., Тихонов А.В., Шибалко К.В. // Письма в ЖТФ. 2002. T. 28. B. 20. C. 1-6.
[5] Li L., Liu L., Wen J., Liu Y. // IEEE Trans. Plasma Sci. 2009. V. 37. N 1. P. 15-22.

[6] Жерлицын А.Г., Исаков П.Я., Мельников Г.В., Слинко В.Н. // Физика плазмы. 2010. Т. 36. В. 2. С. 159-166.

[7] Roy A., Menon R., Sharma V., Patel A., Sharma A., Chakravarthy D.P. // Laser Part. Beams. 2013. V. 31. N 1. P. 45-54.

[8] Дубинов А.Е., Селемир В.Д. // Радиотехника и электроника. 2002. Т. 47. № 6. С. 645-672.

[9] Жерлищын А.Г., Кузнещов С.И., Мельников Г.В., Фоменко Г.П., Цветков В.И. А.с. СССР. № 1522317. БИ. 1989. № 42.

[10] Жерлицын А.Г. // Письма в ЖТФ. 1990. Т. 16. В. 22. С. 78 80.

[11] Jiang W., Shimada N., Prasad S.D., Yatsui K. // IEEE Trans. Plasma Sci. 2004. V. 32. N 1. Pt 1. P. 54-59.

[12] Jeon W., Lim J.E., Moon M.W., Jung K.B., Park W.B., Shin H.M., Seo Y., Choi E.H. // IEEE Trans. Plasma Sci. 2006. V. 34. N 3. Pt 3. P. 937-944.

[13] Zhang Y., Liu G., Shao H., Liang T., Zhang L., Teng Y., Yan L., Lin Y. // IEEE Trans. Plasma Sci. 2011. V. 39. N 9. P. $1762-1767$.

[14] Yang W., Dong Z., Dong Y. // IEEE Trans. Electron Dev. 2016. V. 63. N 9. P. 3713-3718.

[15] Дубинов А.Е., Дубинов Е.Е., Коновалов И.В., Селемир В.Д. // Радиотехника и электроника. 1999. Т. 44. № 3. C. $377-378$.

[16] Grigoriev V.P., Koval T.V., Zherlitsyn A.G., Verkhoturova V., Kanaev G.G. // Adv. Mater. Res. 2015. V. 1084. P. 125-128.

[17] Zhu J., Zhang X., Dang F. // Phys. Plasmas. 2016. V. 23. N 7. P. 072111.

[18] Dang F., Zhang X., Zhang J., Ju J., Zhong H. // J. Appl. Phys. 2017. V. 121. N 12. P. 123305.

[19] Wang H., Zhang J., Dang F., Qian B. // IEEE Trans. Electron Dev. 2019. V. 66. N 7. P. 3178-3183.

[20] Tarakanov V.P. User's Manual for Code KARAT. Springfield, VA: Berkley Research Associates, 1992. 137 p. 
[21] Dubinov A.E., Tarakanov V.P. // Laser Part. Beams. 2017. V. 35. N 2. P. 362-365.

[22] Dang F., Zhang X., Zhong H., Li Y., Qi Z. // Phys. Plasmas. 2014. V. 21. N 6. P. 063307.

[23] Дубинов А.Е., Лойко М.В. // Радиотехника и электроника. 2004. T. 49. № 10. C. 1264-1267. 